\title{
Sobrecarga do cuidado, solidariedade e estratégia de lida na experiência de familiares de Centros de Atenção Psicossocial
}

| 1 Pedro Gabriel Delgado |

Resumo: Os familiares de usuários de serviços de saúde mental que assumem a tarefa do cuidado cotidiano são frequentemente submetidos a sobrecarga objetiva e subjetiva. Estratégias práticas de lidar com a tarefa do cuidado e ações de solidariedade entre familiares podem contribuir para a melhora da qualidade de vida de cuidadores e usuários. Este estudo descreve e analisa estratégia desenvolvida junto a serviços comunitários de saúde mental (CAPS), em colaboração com os familiares, de modo a conhecer melhor a experiência da sobrecarga e apoiar iniciativas de ajuda mútua, educação em saúde e promoção da autonomia. A coleta e análise dos dados utilizou metodologia qualitativa, como observação e grupos focais. Resultados preliminares identificam altos níveis de sobrecarga, boa resposta dos familiares à participação em grupos de ajuda mútua e atividades de educação em saúde, e a necessidade de aperfeiçoar e intensificar as açōes desenvolvidas pelos CAPS para apoio e orientação dos familiares.

Palavras-chave: cuidado em saúde mental; educação em saúde; sobrecarga da família; serviços públicos de saúde mental.
${ }^{1}$ Instituto de Psiquiatria Universidade Federal do Rio de Janeiro. Rio de Janeiro-RJ, Brasil. Endereço eletrônico: pgabriel@ipub.ufrj.br

Recebido em: 04/08/2014 Aprovado em: 17/10/2014 
Quando o valor é o homem, a saúde não pode representar a norma, se a condição humana é a de estar constantemente entre a saúde e a doença. Franco e Franca Basaglia, A Utopia da Realidade, 1974

C'um saber só de experiências feito... Camões, Os Lusíadas, episódio do Velho do Restelo

\section{Introdução}

Os familiares de pacientes que sofrem com transtornos mentais graves e persistentes, quando assumem as incumbências do cuidado cotidiano, frequentemente relatam uma experiência de elevada exigência pessoal, que traz importantes limitaçóes a sua vida diária. Este fato, designado na literatura científica como "sobrecarga familiar" (family burden), é um componente essencial para o entendimento dos desafios de longo prazo inerentes à mudança do modelo de atenção em saúde mental implantado pela Reforma Psiquiátrica no Brasil.

Os serviços comunitários de saúde mental, designados como CAPS - Centros de Atenção Psicossocial, são voltados para o atendimento continuado de usuários portadores de transtornos mentais graves e persistentes (TMGP), e foram implantados no sistema público de saúde brasileiro, de forma mais sistemática, a partir de 2002, após a aprovação da Lei no 10.216. Tais serviços substituem a configuração anteriormente dominante, estruturada através da tríade ambulatórioemergência-hospital psiquiátrico. Por serem abertos e próximos da moradia dos usuários, praticando a atenção psicossocial, os CAPS convocam os familiares a uma nova forma de participação no cuidado, mais presente e cotidiana.

Essa mudança foi vivida inicialmente como desamparo, ecoando as críticas das associações de familiares dos anos 90 (VIANNA, 2002), inseguras com os rumos da substituição do modelo hospitalocêntrico. Com a presença mais visível dos novos serviços nas comunidades, os familiares foram construindo uma interlocução mais permanente com os CAPS, tornando-se parceiros importantes em seu funcionamento e críticos severos de suas fragilidades. A intensidade do cuidado contínuo que lhes é exigido acarreta para os familiares uma enorme sobrecarga, tornando-se desafio crucial da Reforma Psiquiátrica oferecer resposta efetiva a tais necessidades. 
Este artigo apresenta resultados preliminares de uma pesquisa/extensão, realizada de forma colaborativa com a gestão e equipes de serviços municipais de saúde mental da região metropolitana do Rio de Janeiro, e especialmente com familiares de usuários em acompanhamento nos CAPS. ${ }^{1}$ Embora tenha utilizado algumas ferramentas de coleta de dados próprios de métodos quantitativos (como questionários para construção de perfil sociodemográfico e escala de sobrecarga do cuidador), a pesquisa é de natureza predominantemente qualitativa, desenvolvida a partir da escuta da experiência e narrativas dos familiares que aceitaram participar como voluntários. ${ }^{2}$

Alguns conceitos já consolidados no campo da atenção psicossocial foram importantes na formulação do problema, condução da intervenção e posterior análise e discussão do percurso realizado. A concepção de autonomia possível, como linha-mestra do "projeto terapêutico" dos CAPS (LEAL; DELGADO, 2007), ajudou a construir, em parceria com os familiares, as perguntas relacionadas à autonomia dos próprios cuidadores. As experiências de grupos de ajuda mútua, que vêm sendo implantados no Brasil, especialmente através do trabalho liderado por Vasconcelos (2011; 2011a), constituíram referência decisiva. A construção ativa da solidariedade entre pessoas que têm problemas comuns, abraçada com entusiasmo pelos familiares parceiros, permitiu estabelecer correções de rumo no percurso da intervenção.

O compartilhamento do conhecimento, conforme vem sendo definido nos últimos 20 anos na literatura da saúde pública e em outras áreas (JACOBSON, 2007), foi tomado como desafio epistemológico e metodológico da intervenção, visando proporcionar um ambiente de efetiva colaboração e troca entre o grupo de pesquisa e os serviços, como já recomendado por autores deste campo (FARKAS; ANTHONY, 2007).

Esta investigação é parte de um projeto maior, em andamento, que inclui pesquisa e extensão, denominado Familiares Parceiros do Cuidado (FPC), iniciado em agosto de 2011. Os resultados preliminares apresentados neste artigo têm o objetivo de contribuir para o debate dos desafios atuais da Reforma Psiquiátrica, expressos com dramaticidade na oposição entre o complexo desafio do cuidado de usuários portadores de TMGP e a fragilidade estrutural e técnica ainda observada na rede de atenção psicossocial do SUS. 


\section{Familiares e atenção psicossocial: contextualização do problema}

O acompanhamento e apoio às famílias de usuários em atendimento na rede de saúde mental é um importante e urgente desafio da política pública. Os serviços de saúde mental, entre os quais os CAPS, apesar de realizarem, de acordo com as informaçôes disponíveis, açôes terapêuticas e de apoio dirigidas a familiares (DUARTE; KANTORSKI, 2011; BRASIL, 2011; GRIGOLO; DELGADO, 2010; BARROSO; BANDEIRA, NASCIMENTO, 2007; DIMENSTEIN et al., 2010; CAMATTA; SCHNEIDER, 2009; ALMEIDA et al., 2010), não utilizam, de forma sistemática, estratégias de informação, educação em saúde e construção de autonomia, direcionadas a familiares de pacientes esquizofrênicos ou com outros transtornos mentais graves.

Além do acolhimento dos familiares em grupos de apoio e orientação, a experiência internacional sustenta que açōes de: i) educação em saúde; ii) capacitação em habilidades para lidar com as situaçôes da vida diária; e iii) construção de estratégias de solidariedade e ajuda mútua, de modo combinado, mostram resultados efetivos na diminuição das tensōes intrafamiliares, aumento da capacidade autônoma de lidar com as exigências do acompanhamento, melhor interação do paciente com sua família e melhor adesão ao tratamento (DIXON et al., 2001; MARSH; JOHNSON, 1997; MUESER; WEBB; PFEIFFER, 1996; SNOWDEN, 2007; SARACENO, 2007).

As estratégias de intervenção que almejam apoiar familiares de pacientes com TMGP devem ser construídas, desde seu início, com base no compartilhamento das experiências diferenciadas de familiares e de profissionais de saúde no acompanhamento dos casos, de modo a construir conteúdos e métodos pedagógicos culturalmente sensíveis e que produzam sentido para o contexto real de vida dos usuários e suas famílias (BOGART; SOLOMON, 1999; BABLS; ZACAR, 2004; VASCONCELOS, 2011; VASCONCELOS et al., 2011).

A análise de conjunto do acompanhamento de familiares de pacientes esquizofrênicos (ou que sofrem de outros transtornos mentais severos e persistentes) permite que se identifiquem quatro principais modos de intervenção, sustentados por referenciais teóricos diferentes:

i. grupos de suporte social e ajuda mútua, de importante tradição na psiquiatria comunitária inglesa e em organizações de países como Holanda, Canadá 
e Estados Unidos, entre outros, que têm como escopo fundamental a construção de uma autonomia ativa dos familiares no manejo dos problemas, a partir de suas próprias formas de organização (VASCONCELOS, 2011; VASCONCELOS et al., 2011; STENGER, 2011).

ii. o trabalho das associações de familiares vinculados a instituições acadêmicas ou associações médicas, que partem da premissa da informação qualificada sobre o diagnóstico e o tratamento dos transtornos, sob orientação direta de psiquiatras e psicólogos, porém através de organizações juridicamente independentes - o exemplo típico e mais significativo deste grupo é a organização não governamental Schizophrenia Fellowship (composta por familiares, com participação de psiquiatras e outros profissionais de saúde mental), que se tornou consultora permanente da Organização Mundial da Saúde (HARDING, 2002; JEFFS, 2008; WHO, 1998).

iii. a experiência filiada à tradição da "psicoeducação", que se vale de metodologias pedagógicas diversas para atingir a finalidade mais ampla de transmitir informações e competências técnicas sobre o manejo das situações de dependência dos pacientes, e facilitar o recurso mais qualificado à atenção médica, porém sem uma perspectiva clara de construção de grupos autônomos de familiares (DIXON et al., 2001; MUESER; WEBB; PFEIFFER, 1996; BOGART; SOLOMON, 1999; SOLOMON et al., 1997).

iv. intervençõos baseadas na premissa conceitual do vínculo entre as modalidades de "emoções expressadas" e as "recaídas e internações", proposta pelo psiquiatra inglês Julian Leff nos anos 1960 (LEFF; VAUGHN, 1981; 1985; VAUGHN; LEFF, 1976), e que vêm tendo importantes desenvolvimentos desde então, especialmente no contexto da desinstitucionalização de pacientes de longa permanência, implantada como política pública de saúde na Inglaterra desde a mesma época.

As ações mais especificamente "terapêuticas", como consultas, grupos de família, e terapia de família, no cenário dos serviços públicos de saúde mental, constituem uma vertente mais geral das intervençôes, existindo simultaneamente às estratégias específicas descritas nos quatro tipos acima. Esta vertente "terapêutica" na abordagem das famílias (com duas matrizes teóricas dominantes, 
a Psicanálise e a Teoria Sistêmica) convive, influencia e é influenciada pelas estratégias de suporte aos familiares, não sendo possível nem desejável uma separação artificial entre elas. De todo modo, pode afirmar-se que é uma necessidade própria dos CAPS e da atenção psicossocial "repensar a relação entre profissionais e familiares" (MELMAN, 2001), colocando sob tensão dialética o modo de participação dos familiares nos serviços: seja como clientes, seja como protagonistas do cuidado. Esta tensão atravessa todas as etapas do projeto FPC.

\section{Percurso metodológico}

A proposta inicial do projeto FPC foi submetida a uma Oficina Preparatória, em agosto de 2011, com participação de familiares e profissionais convidados, e construída em torno da pergunta: "Como deve se organizar e o que deve conter um curso destinado a familiares de CAPS?". A oficina formulou um roteiro de temas a serem abordados, configurando a primeira versão do curso. O roteiro foi aplicado e submetido a sucessivas avaliações e modificaçôes ao longo das seis "turmas" de familiares. O projeto foi implementado através da realização de seis Ciclos de Encontros (com 5 ou 4 encontros por Ciclo), com duração de 40 horas por Ciclo, ao longo de um período médio de três meses por ciclo. Ao todo, participaram 228 familiares, de 25 CAPS da região metropolitana do Rio de Janeiro. O critério de inclusão no estudo foi: ser familiar de usuário de CAPS e concordar em participar do projeto.

Dentre as atividades preparatórias incluíram-se: contatos com gestores, através de cartas, telefonemas e mensagens eletrônicas; visitas aos serviços e pactuação de parceria. As estratégias metodológicas utilizadas para produção de informaçōes e intervenção foram: ações de educação em saúde mental; lazer e cultura, através de palestras temáticas e atividades lúdicas; observação; grupos focais (rodas de conversa) e entrevistas individuais mediante a aplicação da Escala de Sobrecarga Familiar FBIS-Br (validada no Brasil por BANDEIRA; CALVAZARA, VARELLA, 2005). As técnicas de grupo focal (GF), observação, registros de campo e aplicação do questionário FBIS-Br foram utilizadas para produção das informações. A triangulação destas técnicas se realizou para conferir maior validade ao estudo (MINAYO, 2010) configurando-se como caminhos diferentes para a compreensão do fenômeno - a experiência de ser familiar de uma pessoa com problema mental grave - em sua complexidade. 
Cada encontro foi estruturado de acordo com a seguinte programação: 1) acolhimento e café da manhã; 2) palestras sobre os temas: "Conversando sobre adoecimento mental"; "Entendendo os transtornos mentais"; "Modos e modelos de cuidado em saúde mental"; "Medicamentos psiquiátricos: classificação, modo de funcionamento, efeitos desejáveis e efeitos indesejáveis"; "Benefícios e direitos previdenciários dos familiares e usuários" e "Solidariedade e ajuda mútua entre familiares"; 3) atividades lúdicas e culturais, como: brincadeira de apresentação dos participantes e aquecimento; apresentação de grupo musical formado por usuários e profissionais; atividade expressiva (oficina de pintura) e exibição e debate do filme "O Palhaço" (de Selton Mello); 4) almoço; 5) rodas de conversa (4 encontros) e entrevistas estruturadas individuais (01 encontro); 6) Fórum ampliado de síntese do dia. Ao final de cada ciclo, os participantes que estiveram presentes em pelo menos três encontros ganharam um certificado, e o "Caderno do Participante", uma apostila que continha o conteúdo de todas as aulas, sugerida pelos familiares do I Ciclo. Na semana que antecedia cada encontro, a equipe realizava ligaçóes telefônicas para os familiares e para os CAPS. Ao final de cada ciclo, era feita uma reunião de devolução, em visita agendada com o CAPS e realizada durante a reunião de equipe do serviço, onde os familiares relatavam aos profissionais a experiência de participação no Ciclo de Encontros, seguindo-se uma troca de impressōes entre familiares, pesquisadores e equipe.

Os GFs foram a principal ferramenta metodológica para acessar a experiência dos participantes e facilitar a emergência de narrativas mais próximas ao vivido subjetivo. A escolha do GF se justifica pela criação de ambiência de acolhimento e compartilhamento de saberes e experiência, de suporte e mutualidade. Os grupos foram áudio-gravados e posteriormente transcritos e analisados, e eram formados por familiares seguindo um critério de agrupamento por territórios dos serviços de origem. Parentes de um mesmo núcleo familiar eram incluídos em grupos diferentes. Devido ao fato de a maioria dos familiares serem mulheres, buscou-se incluir mais de um homem em cada grupo. Os temas abordados nas rodas de conversa foram: a) experiência de ser familiar de uma pessoa com transtorno mental grave; b) estratégias de lida: o que facilita ou dificulta a lida cotidiana com o parente portador de transtorno mental; c) relaçôes interpessoais/sociais; e d) relação com o CAPS. Para fins de deste trabalho, iremos analisar as informações 
provenientes das transcrições dos GFs e, de modo complementar, dos relatórios de observação dos encontros e das visitas ao campo.

O material de GF utilizado neste artigo refere-se aos três primeiros ciclos de encontros, totalizando 12 sessões. Os dados descritivos de perfil sociodemográfico são também relativos aos 115 familiares participantes dos três primeiros ciclos, bem como alguns achados da aplicação do questionário sobre sobrecarga do cuidador.

Foi utilizada metodologia qualitativa, baseada em observação e análise dos relatos de experiência. $\mathrm{O}$ material dos grupos foi transcrito e submetido a análise qualitativa de conteúdo, sendo organizado em categorias e grupos de significado (MILLWARD, 2010; TURATO, 2005). O trabalho de campo da pesquisa qualitativa incluiu, além dos GFs: participação em reuniões de equipe e reuniōes de familiares nos CAPS; atividades dos ciclos de encontros, realizados em três locais diferentes da região metropolitana do Rio de Janeiro (capital, Baixada Fluminense e região de Niterói/São Gonçalo/Itaboraí); realização e participação em dois Congressos de Familiares Parceiros do Cuidado (2012 e 2013). Os dados de perfil sociodemográfico são utilizados apenas para finalidade descritiva, de caracterização geral do grupo estudado.

\section{Resultados e Discussão}

\section{Perfil dos participantes}

Concluíram os Ciclos 228 familiares, significando aproximadamente $80 \%$ de adesão. A caracterização sociodemográfica dos participantes (com base nos dados já consolidados, referentes aos três primeiros ciclos), que não pode ser extrapolada para o universo de familiares, mostra que predominam mulheres cuidadoras $(80 \%$ a $20 \%)$, semelhante ao que aparece em outros estudos (BARROSO; BANDEIRA; NASCIMENTO, 2007). A tarefa do cuidado tem evidente marca de gênero, e as diferenças no relato de experiências de homens e mulheres serão objeto de análises posteriores. Em relação ao parentesco, as mães formavam a maioria dos cuidadores (44\%), seguidos de irmã ou irmão (31\%), pai (10\%), filha (1\%), e outros (cunhada, sobrinho, tio e outros, com $14 \%)$. Cerca de $60 \%$ moravam com o usuário acompanhado. Quanto ao estado civil, cerca de metade dos participantes era formada por pessoas casadas ou que viviam com companheiro, sendo $20 \%$ viúvos, $19 \%$ solteiros e $15 \%$ separados ou 
divorciados. Quanto à faixa etária: 7,48\% tinham entre 21-40 anos; 62,62\%, de

41 a 60 anos; $28,97 \%$, de 61 a 80 anos, havendo um participante com mais de 80 anos. Quanto à renda familiar, $47 \%$ recebiam menos que dois salários mínimos, $36 \%$ entre dois e quatro salários mínimos e apenas $14 \%$ tinham renda maior que quatro salários mínimos. O perfil de escolaridade, em anos completos de estudo, mostrava: 2,8\% sem escolaridade; $11 \%$ até quatro anos; $33 \%$ de cinco a oito anos; $32 \%$ de nove a 12 anos; e 14\% com mais de 13 anos de vida escolar. Em relação à vida laborativa, 21\% estavam aposentados, 36\% estavam empregados e $37 \%$ referiam trabalhar no próprio lar ou estar desempregados.

Um dado relevante do perfil sociodemográfico dos familiares foi a elevada adesão religiosa: $27 \%$ se declararam católicos; $59 \%$, evangélicos; $2,8 \%$, espíritas; e 6,5\%, sem religião. A religiosidade, como se verá a seguir, desempenha papel de grande importância na vida dos familiares e na própria experiência do cuidado. Sobre o acesso ao CAPS, medido pelo "tempo gasto para chegar de sua casa ao CAPS", os dados mostravam facilidade de acesso: $46 \%$ chegavam ao serviço com menos de 30 minutos, e $24 \%$ entre 30 minutos e uma hora; $58 \%$ declararam que o acesso ao CAPS era "fácil" ou "muito fácil". O cuidador típico era, portanto: mulher, com mais de 50 anos, casada, com baixa renda familiar, escolaridade: ensino fundamental incompleto, evangélica, residindo com o usuário, em casa própria, localizada no território geográfico de abrangência do CAPS.

\section{Experiência de ser familiar de uma pessoa com problema mental grave}

Os participantes qualificam a experiência de ser familiar de uma pessoa com transtorno mental grave como uma experiência "difícil", "estressante" e de "sobrecarga", principalmente no momento de início da doença, "crise" ou agravamento dos sintomas, o que corresponde ao observado na literatura (SARACENO, 2001; LEFLEY, 2005; ROSE, 1996; MAURIN; BOYD, 1990). Mediante a análise das narrativas, observa-se que o vivido subjetivo dos familiares engloba os mais variados sentimentos, nomeados como: "vergonha", "medo", “irritação", "pressão", "raiva”, "tristeza”, "cansaço”, “culpa”, "pânico”, "rejeição”, "ansiedade", "preocupação", "preconceito", "solidão", "fracasso"; "paciência”, "força”, "amor", "fé”, "solidariedade", "responsabilidade", "respeito", "satisfação" em cuidar, "companheirismo" e "esperança". Tais sentimentos/estados emocionais compõem um mosaico de modalidades experienciais, por vezes contraditórias, 
conforme já apontado na formulação clássica de Bateson (1972), entre outros autores (SARACENO, 2001; NICHOLS; SCHWARTZ, 2007; FALLOON, 2003). A construção de sentidos compartilháveis e acessíveis ao senso comum, assim como a busca pela compreensão da experiência de si e do outro, diante do enigma da vida e da incompreensibilidade do fenômeno do adoecimento mental, inscrevem as narrativas em um campo intersubjetivo, numa temporalidade onde a distinção entre passado, presente e futuro parecem colapsar, reforçando o caráter contínuo da experiência na consciência, conforme ilustrado no relato:

A princípio [...] ter um filho portador de um transtorno de mental foi difícil pra mim, pra toda mãe [...], todo familiar, mas principalmente pra mãe, que a mãe, assim, é amor incondicional [...]. Então, pra mim, foi muito difícil no começo, porque era o desconhecido, eu não tinha a menor noção como é que ia ser a minha vida, se eu ia trabalhar, se eu podia sair, aí fiquei com muito medo, me assustou muito, hoje é tudo normal [...], tudo foi se consertando.

A identificação do problema pelo familiar e a sensação de "não saber o que [o paciente] tem" é acompanhada pelo sentimento de angústia dos familiares, que mobilizam processos pessoais de busca por modelo explicativo sobre origem da doença, e mesmo de busca por ajuda e/ou tratamento. A esse respeito, um pai de 84 anos, viúvo, com 04 filhos com problemas mentais relata:

Minha experiência aí é a seguinte, [...] a doença da minha família veio da avó, minha sogra, que não conheci, e era doente mental. Conheci a mãe dos meus filhos, ela tinha problemas mentais, mas não apresentava, ela foi apresentar os problemas seis anos depois de convivência [...]. Aí, depois que eu a conheci começou a nascer o primeiro filho [...]. Tratei dele no hospital, não é isso? Nasceu a segunda, também com problema, mas só que esse problema dos filhos só começam depois de 14 pra 15 anos, não começa antes [...] eu não entendo, sabia?!

No relato de diversos familiares, o contato com psiquiatras através de consultas médicas e no momento de comunicação do diagnóstico revela um prognóstico sombrio para o paciente. Este achado pode sinalizar que a crença na esquizofrenia como doença necessariamente crônica e degenerativa ressalta a força que o "legado kraepeliniano" ainda tem na perspectiva médico-psiquiátrica, conforme já sinalizado por Davidson (2003). Alguns familiares falam do sentimento de impotência e tristeza ao saberem que o problema de seu parente não tem cura, conforme o relato de um pai:

Puxa, a pior coisa que tem é chegar num determinado lugar e o médico dizer que não tem cura. Isso é uma confissão de fracasso que eu, como técnico ligado à matemática, 
eu ficava fuzilando: "como é que um médico vem me dizer", desculpa, "vem dizer que não tem cura?!” Caramba... cadê a ciência aí!?

No entanto, a necessidade de um diálogo criativo e do compartilhamento do conhecimento é expressa também com ênfase, como um apelo ("alguém me explica aí o que é a esquizofrenia? Para que eu possa cuidar melhor da minha filha!") ou uma crítica ("por que nos CAPS não nos explicam melhor como funcionam os remédios?").

Alguns familiares ressaltam que o cuidado é um aprendizado permanente, que consiste em colocar em diálogo aquilo que os profissionais dizem sobre o sofrimento mental e o que o cuidador é capaz de aprender com sua própria experiência, se se colocar aberto e disponível:

No princípio, eu não entendia o que se passava com minha irmã. Aí comecei a tentar entender. Até hoje ainda não entendo, mas estou sempre aprendendo, cada dia aprendo uma coisa nova.

Em dois momentos das atividades de educação em saúde, este esforço de compartilhamento de saberes se mostrava mais evidente: quando se apresentavam e se discutiam as noções de psicopatologia e de tratamento farmacológico. O "saber de experiências feito" dos familiares enriquecia as "palestras" com casos, situações e exemplos da faina diária do cuidado, apresentando questões dirigidas a todos os participantes, e não apenas ao profissional que conduzia a apresentação do tema. Esta dinâmica era favorecida pela presença dos familiares concluintes de cursos anteriores, que atuavam como instrutores, e pelo fato de que os temas mais técnicos só eram abordados depois dos encontros iniciais, voltados para o relato da experiência de cuidar e para a sensibilização quanto ao conhecimento já adquirido através do convívio diário com seu familiar.

A proposta de "aprendizado através de parceiros" (peer education), no campo da Saúde Pública, supõe que os tutores, cujo saber tem grande aceitação e credibilidade, justamente por nascer da experiência, sejam eles próprios sujeitos da forma de transmissão do conhecimento que desenvolvem, sentindo-se "empoderados" em sua nova prática (TURNER; SHEPHERD, 1999), o que dificilmente ocorreria se os familiares se colocassem na mera posição de audiência de palestras científicas ou técnicas. Desta forma, os temas mais específicos da psiquiatria científica, como a psicopatologia e a psicofarmacologia, puderam ser 
abordados sob a forma de um real compartilhamento de saberes nascidos de origens muito diversas ("científico" ou "laico").

\section{Sobrecarga}

O tema da sobrecarga e a "pressão" sofrida pelos familiares foi muito presente nas narrativas dos participantes, que, apesar de vivenciarem esta experiência em maior ou menor grau, e de criarem estratégias singulares para a lida cotidiana e superação (SPANIOL; ZIPPLE, 1994) do problema, na maioria dos casos também vivenciam a experiência de adoecimento junto com o usuário, necessitando de cuidados para restabelecerem sua saúde física e mental, conforme observado na literatura (SARACENO, 2001; LEFLEY, 2005; FALLOON, 2003; FARKAS; ANTHONY, 2010) e na fala de alguns familiares:

Nós somos um balde que a gente transborda. Uma panela de pressão, a qualquer momento o pino pode estourar, rodar, rodar e subir.

Mas olha, veja, nós mães também, a gente precisa de um psicólogo, sinto que a gente precisa de um profissional pra sentar e nos orientar, pra nos confortar. A gente também fica desbaratinado, né?

A experiência da sobrecarga assume às vezes uma dimensão próxima do insuportável:

Tentei me matar uma vez com ele, porque não tava aguentando a carga sozinha, tentei me jogar debaixo do trem do metrô.

O sentimento de "medo" e preocupação dos familiares em relação ao processo de envelhecimento e ao futuro de seu parente, caso venham a "faltar", aspecto também associado ao sentimento de sobrecarga, foi muito presente no relato dos familiares:

É como eu tava falando, eu também fico um pouco preocupada [...], porque nós estamos aqui de passagem, e tenho muito medo de amanhã ou depois eu partir... como vai ficar meu filho?!

O preconceito dentro da própria família e o sentimento de solidão no cuidado cotidiano ao parente foram aspectos muito presentes na fala dos familiares. Conforme já sinalizado por Giddens (2005) e Duarte (1995; 2003), a família aparece como célula social que tem importante papel na reprodução social, percepção presente no relato a seguir, relacionado ao estigma associado ao transtorno mental: 
O doente mental ele é abandonado [...], excluído da família, aí tem um que se levantar pra poder ajudar, sempre tem um pra fazer a diferença [...], porque eles não são só abandonados pelos parentes, a sociedade começa no lar, o abandono socialmente falando começa no lar, mas ele vai além, vai e volta, vai pra escola, vai pros vizinhos, você tá entendendo?

De acordo com os familiares, o "abandono" da família e a discriminação, além de serem emocionalmente desgastantes, aumentam a sobrecarga, produzindo efeitos concretos para a vida cotidiana, como: ter menos tempo livre para as atividades diárias, para o lazer e para o cuidado de si; ter menos recurso financeiro; ter de "largar o trabalho" para cuidar do parente, o que, de acordo com um irmão, "compromete a nossa vida pessoal". A esse respeito, alguns familiares expressam a dimensão da sobrecarga objetiva:

Porque eu tive que largar o trabalho [...] pra eu ver o meu filho bem, bem mesmo, eu falei: "Vou largar tudo, porque senão eu vou ver meu filho morto de gente se aproveitar dele".

Perde também um pouco da vida social, né? [...], você se dedica tanto e às vezes nem tem tempo pra gente sair, passear, entendeu? Porque a dedicação é exclusiva, né?!

Muitos familiares relataram situaçôes de violência sofrida ou provocada pelo usuário, além de outras situaçôes-limite, conforme o relato a seguir:

Era insistente, era uma coisa persistente, assim, de azucrinar. Aí começou, quis tocar fogo na cozinha, no meu quarto, na cortina, com raiva [...]. Ele jogava açúcar, abria o saco de açúcar e jogava na cozinha toda [...], espalhava tudo, era agressivo... muita agressividade... foi desenvolvendo muita agressividade. Eu não tinha mais sossego, eu não tinha mais nada.

\section{Estratégias de lida}

O tema "estratégias de lida" refere-se às atitudes e ações desenvolvidas em resposta às situações da vida cotidiana. Refere-se também ao modo de se relacionar com o usuário. Identificaram-se diversas estratégias pessoais, por vezes contraditórias e não necessariamente excludentes, que revelam caminhos singulares de ser e estar no mundo, na relação com o outro, e de fortalecimento pessoal, tal como já apontado em outros trabalhos (CORIN, 1990; DAVIDSON, 2003; VASCONCELOS, 2007). Estratégias como o "diálogo" e a "negociação", assim como o exercício de se colocar no lugar do outro, de "respeitar", evitar "o confronto" ou "contornar a situação" foram as mais utilizadas, ressaltando desta forma a dimensão dialógica e intersubjetiva da experiência humana: 
Eu acho que não contrariando, não entrando em choque, não dizendo, por exemplo, que "você é preguiçoso", "você é incompetente", "você é doente", [...] ajuda muito. Então, minha linha de comportamento em relação a ele é não exigir muito, é não exigir dele o que ele não pode fazer [...], pois isso acirra o sistema nervoso dele, isso prejudica de maneira que pode levar a uma situação tensa.

Em alguns casos, os familiares lançam mão da "chantagem" como parte do processo de negociação:

Ele tem um pavor de internação, sabe que é muito sério, quando você falarem internação, ele começa a ficar pianinho [...], esse é meu último truque...

O caráter restritivo e negativo da internação foi observado em diferentes situaçôes e narrativas suscitadas no contexto do projeto. Em geral, os familiares identificam as diferenças existentes entre o modelo de tratamento manicomialhospitalar e o modelo de cuidado comunitário em saúde mental, enfatizando que um dos efeitos produzidos pela internação é desconexão com os laços sociofamiliares (SARACENO, 2001; THORNICROFT; TANSELLA, 2010). Em muitas circunstâncias, os familiares diziam: "é melhor ficar em casa", apesar da crise, por exemplo, embora muitas vezes também reconhecessem a internação como um recurso terapêutico necessário. A experiência, presente em alguns relatos, de longas internações de seu familiar em momentos anteriores de sua vida, não foi, no entanto, associada a menor sobrecarga subjetiva ou objetiva, do mesmo modo que no estudo de Barroso, Bandeira e Nascimento (2007, p. 276). Entretanto, é relatada também a experiência de "desamparo" diante das situaçōes de crise, se ocorrem dificuldades de conseguir um atendimento imediato.

Alguns familiares também ressaltam a importância de se "ter pulso" e até de entrar "em conflito", em alguns momentos, para impor certos limites durante a negociação. Sinalizam a importância de se "tratar [o usuário] que nem uma pessoa normal”, o que nos parece uma estratégia de interrupção do ciclo de reprodução social do estigma. Houve casos, porém, em que ao perceber o agravamento da situação no momento da negociação, o familiar acabava por "fazer as vontades" do usuário, conforme o relato de um pai:

$\mathrm{Eu}$, no começo, batia de frente e a coisa não funcionava, ele ficava nervoso e terminava saindo de casa ali naquele momento [...]. Depois, né, conversando, fui aprendendo que às vezes ali, com razão que a gente tem, é melhor a gente ficar calado, que aquela pessoa acha que ela tá com a razão e nesse momento, você ficando calado, com razão que você tem, você ganha a questão. 
$\mathrm{Na}$ perspectiva dos familiares, levar o usuário para sair, distrair, brincar, passear, fazer atividades juntos e estimular sua participação na vida comunitária e no CAPS são estratégias muito utilizadas, de modo que a incorporação das diferentes dimensóes da vida cotidiana e da vida comunitária, como, por exemplo, o morar e o tempo livre (LEFLEY, 2005), se incorporam ao cuidado diário, conforme o relato de um pai:

O meu é o seguinte, ele tava muito estressado ontem, aí falei pra ele assim: "Vem cá, você tá estressado, por causa de quê? Já almoçou?” [...] Aí eu tava fazendo um servicinho em casa, né, então falei: "vou terminar de fazer um servicinho aqui e a gente vai lá pra casa do seu irmão" [...]. Aí ele andou pra caramba comigo de bicicleta, é claro, de pé ele não gosta de andar.

Estratégias relacionadas para tornar a vida "mais leve” e alívio da sobrecarga, tanto objetiva quanto subjetiva, foram muito presentes nas narrativas dos familiares. Não encarar o problema "como um fardo", "ter humor", passear, se divertir, "dar uma fugida", "tocar um instrumento" e "fazer o que gosta" são algumas estratégias utilizadas, conforme o relato de uma mãe e um pai, respectivamente:

Pra eu poder ter mais leveza, cuidar dele com mais leveza [...] dou minhas fugidinhas, vou pro forrozinho [...], vou tomar minha cervejinha, vou pro videokê cantar...

Tem hora que o coração dói. Aí eu vou pra música, que é meu refúgio.

O cuidado de si, cuidados com o corpo e com a saúde física e mental, foi uma estratégia muito presente na fala dos familiares, principalmente entre as mulheres, que ressaltam a importância de cuidar da beleza:

Hoje eu vou tirar o dia pra mim. Vou no salão fazer uma unha, que às vezes eu fico meses sem conseguir pintar o cabelo, fazer uma unha, daí falei: "não, tenho que tirar pelo menos, já que eu não tenho convívio social, pelo menos de vez em quando tenho que me arrumar, né?!" Por que senão fica assim, bem pesado.

De acordo com os familiares, sentimentos ou estados emocionais como "amor", persistência", "força" e "esperança” são elementos essenciais para superar o sofrimento suscitado na vida cotidiana e para o fortalecimento pessoal, conforme também apontado por Davidson (2003) e Vasconcelos (2007; 2011).

Ressalte-se a valorização da fé, da religiosidade, da oração e/ou da crença em Deus ou em alguma religião, temas recorrentes na fala dos familiares e estratégia para não se desistir da "luta" e perder a esperança. Em alguns casos, 
a religiosidade não necessariamente corresponde à participação em uma ordem religiosa, conforme o relato abaixo:

É difícil, mas a gente [...] tem que pedir força. Uma coisa que também dá muita força pra gente é a fé. Eu não tenho religião [...], a minha religião é Deus [...]. Agora, eu tenho muita fé. Eu faço minhas orações todos os dias, sabe, isso eu acho que é importante pra caramba, né, a religiosidade [...].

"Pedir ajuda" ao CAPS, aos amigos e familiares para realização de atividades da vida diária e para buscar tratamento para problemas de saúde (física e mental) - como "pressão alta", "ansiedade", "depressão", "estresse" - foram ações comuns entre muitos familiares, o que reforça a importância de inclusão da família no tratamento no CAPS, ou outros dispositivos de atenção à saúde mental, e da existência da rede de suporte social e ajuda mútua, conforme os relatos abaixo:

Às vezes, a gente tem que pedir ajuda, a gente pede ajuda pelo CAPS, a gente pede ajuda a pessoas conhecidas, vizinhos [...].

Então, tive que ter acompanhamento psicológico. Até pra lidar com a coisa. Tem gente que diz que eu lido com muita facilidade. Não é. Tive que ter acompanhamento psicológico pra poder encarar as coisas como eu encaro...

Embora muitos relatos mencionem o afastamento dos vizinhos e amigos, e a consequente sensação de isolamento que passa a ser experimentada pelo cuidador, a iniciativa de pedir ajuda a outras pessoas do mesmo bairro é também mencionada como estratégia de lidar com a continuidade do cuidado e os imprevistos:

Mas o que que eu passei a fazer? Lá fora, no meu bairro, eu dei meu telefone pra todo mundo. Caminhão tem meu telefone. Motorista, dono de botequim, dono de bar, dono de padaria. Lá quase todo mundo tem meu telefone. [...] Já aconteceu de eu sair correndo e cuidar do meu irmão.

Assim como observado na literatura (SARACENO, 2001; FALLOON, 2003; BROWN; BIRLEY; WING, 1972; CAROL et al., 1980), aspecto muito recorrente e consensual nas narrativas dos familiares foi o tema da necessidade de "conhecimento"/“informação"/"compreensão" sobre a doença mental, diagnóstico e tratamento. A maioria dos familiares relatou que a ausência desse "esclarecimento" e de uma "explicação" atrapalham a lida cotidiana, o que justifica a existência de abordagens psicoeducativas e/ou educação em saúde mental. De acordo com eles, a falta de iniciativas das equipes dos serviços para orientação sobre como lidar com a situação é um problema. Apesar disso, alguns participantes reconhecerem que, a partir do tratamento no CAPS, passaram a 
entender e a lidar melhor com a situação, como no relato já mencionado da mãe

que chegou ao CAPSi com o apelo: "pelo amor de Deus! Me explica o que é esquizofrenia! Me ensina a cuidar da minha filha”.

\section{Considerações finais}

"Estamos no mesmo barco", exclama uma participante, apoiada pelos pares da mesma roda de conversa, e ecoando a reflexão de um pai, assíduo em vários Ciclos de Encontros, sobre a necessidade de reforçar a participação nas "assembleias" de familiares dos CAPS. Assim como na metodologia dos grupos de ajuda mútua, entre os Familiares Parceiros a solidariedade se expressa com o compartilhamento das difíceis experiências do cuidado, o que traz "leveza" à percepção da história de cada um dos participantes: "vendo os problemas dos outros, percebo que os meus nem são tão pesados”. Solidariedade, ajuda mútua, compartilhamento da experiência e do saber adquirido, responsabilidade e compromisso militante com a fiscalização dos serviços públicos vão formando a argamassa de sustentação da parceria construída.

Nos dois congressos realizados (2012 e 2013), os relatos recolhidos dão conta de benefícios obtidos com a participação no projeto, através de sentimentos e percepções como: "me sinto mais seguro, mais leve"; "consegui organizar melhor minha vida"; "viajei de férias pela primeira vez, e meu filho ficou bem sozinho"; "estamos ajudando a organizar o grupo de familiares no nosso CAPS"; "tenho mais facilidade de perguntar as coisas ao psiquiatra”. A demanda por continuidade do projeto aparece em todas as rodas de conversa, e a elevada adesão a encontros longos, realizados aos sábados, às vezes em locais muito distantes da moradia do familiar, aponta para um reconhecimento de benefícios alcançados. Porém, a avaliação da efetividade objetiva da intervenção está sendo realizada através de outras estratégias metodológicas, que escapam aos limites deste artigo.

O projeto busca construir suas referências no campo da avaliação (FURTADO; ONOCKO, 2008) das políticas públicas intersetoriais de saúde mental, da antropologia das organizações e práticas em saúde (SAILLANT; GENEST, 2012; VELHO, 1981) e da atenção psicossocial.

A equipe de pesquisadores (psiquiatra, antropóloga, psicóloga, enfermeira, dois terapeutas ocupacionais) e estagiários (18 estudantes de graduação - de Medicina, Psicologia, Serviço Social, Enfermagem e Terapia Ocupacional - 
passaram pelo projeto em alguma fase) descreve também, nos relatos pessoais solicitados ao longo do projeto, o impacto positivo da prática desenvolvida em sua formação e na compreensão mais aprofundada tanto da experiência do adoecimento e do cuidado, como dos componentes de acesso ao tratamento com autonomia - parte do desafio da equidade em saúde (SEN, 2010).

\section{Agradecimentos}

A todos os familiares do projeto Parceiros do Cuidado. Às equipes dos CAPS participantes. Aos pesquisadores e alunos que integraram a equipe do projeto no Núcleo de Pesquisas em Políticas Públicas de Saúde Mental, do Instituto de Psiquiatria da UFRJ (NUPPSAM), especialmente Sílvia Monnerat, Catarina Dahl, Melissa Ribeiro, Abmael Alves, Anansa Moraes, Fabiana Solis e Tiago Bezerra.

\section{Referências}

ALMEIDA, M.M. et al. A sobrecarga de cuidadores de pacientes com esquizofrenia. Revista de Psiquiatria do Rio Grande do Sul. Porto Alegre, v. 32, n. 3, out. 2010. Disponível em: <http://www.scielo.br/pdf/rprs/v32n3/1312.pdf> Acesso em: 13 ago 2014.

BABLS, S.C.; ZACAR, F.M.H. A família e as abordagens psicossociais na esquizofrenia. Revista Psicologia Argumento. Rio de Janeiro, v. 22, n. 39, p. 27-34, out-dez 2004.

BANDERIA, M.; CALVAZARA, M,G. P; VARELLA, A.A.B. Escala de sobrecarga dos familiares de pacientes psiquiátricos: adaptação transcultural para o Brasil (FBIS-BR). Jornal Brasileiro de Psiquiatria. Rio de Janeiro, v. 54, n. 3, p. 206-214, 2005. Disponível em: < http://www.ufsj.edu.br/portal2-repositorio/File/lapsam/Artigos\%20digitalizados/ Escala\%20FBIS-BR.PDF> Acesso em: 14 ago 2014.

BARROSO, S.M.; BANDEIRA, M.; NASCIMENTO, E. Sobrecarga de familiares de pacientes psiquiátricos atendidos na rede pública. Revista de Psiquiatria Clínica. São Paulo, v. 34, n. 6, p. 270-277, 2007. Disponível em < http://www.scielo.br/pdf/rpc/v34n6/ v34n6a03.pdf> Acesso em: 12 ago 2014

BASAGLIA, F. A utopia da realidade (1974). In: Escritos selecionados em saúde mental e reforma psiquiátrica. Rio de Janeiro: Garamond, 2005, p. 225-236.

BATESON, G. Toward a theory of Schizophrenia. In: . Steps to an ecology of mind. San Francisco: Chandler, 1972, p. 205-232.

BOGART, T.; SOLOMON, P. Procedures to share treatment information among mental health providers, consumer, and families. Psychiatric Services, v. 50, n. 10, p. 1321-1325, out 1999. Disponível em: < http://journals.psychiatryonline.org/data/Journals/PSS/3525/1321. pdf> Acesso em: 13 ago 2014. 
BRASIL. Ministério da Saúde. Secretaria de Atenção à Saúde. DAPES. Coordenação Geral de Saúde Mental, Álcool e Outras Drogas. Saúde Mental no SUS: as novas fronteiras da Reforma Psiquiátrica. Relatório de Gestão 2007-2010. Brasília: Ministério da Saúde 2011, 106 p. Disponível em: <http://bvsms.saude.gov.br/bvs/publicacoes/saude_mental_fronteiras_ reforma_psiquiatrica.pdf> Acesso em: 12 ago 2014.

BROWN, G.W.; BIRLEY, J.L.T.; WING, J.K. Influence of Family Life on the Course of Schizophrenia Disorders. Brititish Journal of Psychiatry, v. 121, n. 562, p. 241-58, set. 1972. Disponível em: < http://bjp.rcpsych.org/content/121/562/241.full.pdf+html> Acesso em: 13 ago 2014.

CAMATTA, M.W.; SCHNEIDER, J.F. O trabalho da equipe de um Centro de Atenção Psicossocial na perspectiva da família. Revista da Escola de Enfermagem da USP. São Paulo, v. 43, n. 2, p. 393-400, jun 2009. Disponível em: < http://www.scielo.br/pdf/reeusp/v43n2/ a19v43n2.pdf >. Acesso em: 13 ago 2014.

CAROL, M. et al. Family Treatment of Adult Schizophrenic Patients: a psychoeducational approach. Schizophrenia Bulletin, v. 6, n. 3, p. 490-505, 1980. Disponível em: < http://schizophreniabulletin.oxfordjournals.org/content/6/3/490.full.pdf +html> Acesso em: 13 ago 2014.

CORIN, E. Facts and Meaning in Psychiatry. An anthropological approach to the lifeworld of schizophrenics. Culture, Medicine and Psychiatry, v. 14, n. 2, p. 153-188, jun. 1990. Disponível em: <http://link.springer.com/article/10.1007\%2FBF00046659> Acesso em: 13 ago 2014.

DAVIDSON, L. Living outside mentalillness. Qualitative studies of recovery in schizophrenia. New York: University Press, 2003.

DIMENSTEIN, M. et al. Estratégia da Atenção Psicossocial e participação da família no cuidado em saúde mental. Physis: revista de saúde coletiva. Rio de Janeiro, v. 20, n. 4, p. 1209-1226, dez 2010. Disponível em: < http://www.scielo.br/pdf/physis/v20n4/a08v20n4. pdf>. Acesso em: 13 ago 2014.

DIXON, L. et al. Evidence-Based Practices for Services to Families of People with Psychiatric Disabilities. Psychiatric Services, v. 52, n. 7, p. 903-910, jul. 2001. Disponível em: <http:// ps.psychiatryonline.org/data/Journals/PSS/3571/903.pdf> Acesso em: 13 ago 2014.

DUARTE, L.F.D. Horizontes do Indivíduo e da Ética no Crepúsculo da Família. In: RIBEIRO, I.; RIBEIRO, A.C.T. (Orgs.). Família em Processos Contemporâneos: inovaçōes culturais na sociedade brasileira. São Paulo: Loyola, 1995, p. 27-42.

DUARTE, L.F. D. Indivíduo e pessoa na experiência da saúde e doença. Ciência e Saúde Coletiva, v. 8, n. 1, p. 173-183, 2003. Disponível em: < http://www.scielo.br/pdf/csc/v8n1/ a13v08n1.pdf> Acesso em: 13 ago 2014.

DUARTE, M.L.C.; KANTORSKI, L. P. Avaliação da atenção prestada aos familiares em um centro de atenção psicossocial. Revista Brasileira de Enfermagem. Brasília, v. 64, n. 1, p. 47-52, fev. 2011. 
FALLOON, I.R.H. Family interventions for mental disorders: efficacy and effectiveness. World Psychiatry, v. 2, n. 1, p. 20-28, fev 2003. Disponível em: < http://www.ncbi.nlm.nih. gov/pmc/articles/PMC1525058/pdf/wpa020020.pdf> Acesso em: 13 ago 2014.

FARKAS, M.; ANTHONY, W.A. Bridging science to service: Using Rehabilitation Research and Training Center program to ensure that research-based knowledge makes a difference. Journal of Rehabilitation Research \& Development, v. 44, n. 6, p. 879-892, abr. 2007. Disponível em: <http://www.rehab.research.va.gov/jour/07/44/6/pdf/farkas.pdf> Acesso em: 13 ago 2014.

FARKAS, M.; ANTHONY, W.A. Psychiatric rehabilitation interventions: a review. International Review of Psychiatry, v. 22, n. 2, p. 114-129, abril 2010. Disponível em: http:// informahealthcare.com/doi/abs/10.3109/09540261003730372 Acesso em: 13 ago 2014.

FURTADO, J.; ONOCKO CAMPOS, R. O percurso da pesquisa avaliativa de uma rede de Centros de Atenção Psicossocial: entre a saúde coletiva e a saúde mental. In: ONOCKO CAMPOS, R. et al. Pesquisa avaliativa em saúde mental. Desenho participativo e efeitos da narratividade. São Paulo: Hucitec, 2008, p. 189-207.

GIDDENS, A. Sociologia. Porto Alegre: Artmed, 2005.

GRIGOLO, T.M.; DELGADO, P.G.G. Avaliar-CAPS. Um retrato dos serviços substitutivos no Brasil. In: LANCETTI, A.; CAMPOS, F. (Org.). Experiências da Reforma Psiquiátrica no Brasil. São Paulo: Hucitec, 2010, p. 379-388.

HARDING, C.M. Beautiful minds can be recovered. Mental Illness Fellowship Victoria. Disponível em: http:/www.mifellowship.org/sites/default/files/styles/Fact\%20Sheets/ Beautiful\%20Minds.pdf . 2002

JACOBSON, N. Theory for the "fourth wave" of knowledge transfer and exchange research. Science communication, v. 29, n. 1, p. 116-127, set 2007. Disponível em: < http:// scx.sagepub.com/content/29/1/116.full.pdf+html> Acesso em: 13 ago 2014.

JEFFS, S. Be loyal to wellness. Mental Illness Fellowship Victoria. Disponível em: <file:///C:/ Users/Ana\%20Silvia/Downloads/Be\%20loyal\%20to\%20wellness.pdf>. 2008

LEAL, E.M.; DELGADO, P.G.G. Clínica e cotidiano: o CAPS como dispositivo de desinstitucionalização. In: PINHERIO, R. et al. (eds.) Desinstitucionalização na saúde mental: contribuições para estudos avaliativos. Rio de Janeiro: Cepesc, 2007, p. 137-154.

LEFF, J.P.; VAUGHN, C. Expressed emotion in families: its significance for mental illness (Series Title) New York: Guilford Press, 1985.

LEFF, J.; VAUGHN, C. The role of maintenance therapy and relatives' expressed emotion in relapse of schizophrenia: a two year follow-up. British Journal of Psychiatry, v. 139, n. 2, p.102-104, ago. 1981. Disponível em: http://bjp.rcpsych.org/content/139/2/102.full. pdf+html Acesso em: 13 ago 2014. 
LEFLEY, H.P. O papel das famílias na integração comunitária: A promoção de serviços de saúde mental, investigação e recovery. In: ORNELAS, J. et al. Participação e empowerment das pessoas com doença mental e seus familiares. Lisboa: AEIPS, 2005, p. 57-79.

MARSH, D.T.; JOHNSON, D.L. The family experience of mental illness: implications for intervention. Professional Psychology Research and Practice, v. 28, n. 3, p. 229-237, 1997. Disponível em: < http://psycnet.apa.org/journals/pro/28/3/229.pdf> Acesso em: 13 ago 2014. MAURIN, J.T.; BOYD, C.B. Burden of Mental Illness on the Family: A Critical Review. Archives of Psychiatric Nursing, v. 4, n. 2, p. 99-107, abril 1990. Disponível em: < http:// www.sciencedirect.com/science/article/pii/088394179090016E\#> Acesso em: 13 ago 2014. MELMAN, J. Família e doença mental. São Paulo: Escritura, 2001.

MILLWARD, L. Grupos focais. In: BREAKWELL, G. et al. (orgs.). Métodos de Pesquisa em Psicologia. Porto Alegre: Artmed, 2010, p. 278-301.

MINAYO, M.C. Conceito de avaliação por triangulação de métodos. In: MINAYO, M.; ASSIS, S.; SOUZA, E. Avaliação por triangulação de métodos. Rio de Janeiro: Fiocruz, 2010, p. $19-50$.

MONNERAT, S. et al. Familiares parceiros do cuidado. Relatório preliminar de pesquisaintervenção. Rio de Janeiro: NUPPSAM/IPUB/UFRJ, dez de 2012.

MUESER, K.T. et al. Family burden of schizophrenia and bipolar disorder: perceptions of relatives and professionals. Psychiatric Services, v. 47, n. 5, p. 507-511, maio 1996. Disponível em: < http://ps.psychiatryonline.org/article.aspx?articleID=79319> Acesso em: 13 ago 2014.

NICHOLS, M.P.; SCHWARTZ, R.C. Terapia familiar. Conceitos e métodos. Porto Alegre: Artmed, 2007.

ROSE, L.E. Families of psychiatric patients: a critical review and future research directions. Archives of Psychiatric Nursing, v. 10, n. 2, p. 67-76, abril 1996. Disponível em: <http:// www.sciencedirect.com/science/article/pii/S0883941796800690> Acesso em: 13 ago 2014. SAILLANT, F.; GENEST, S. Introdução. In: SAILLANT, F.; GENEST, S. (Orgs). Antropologia médica: ancoragens locais, desafios globais. Rio de Janeiro: Fiocruz, 2012, 19-36. SARACENO, B. et al. Barriers to improvement of mental health services in low-income and middle-income countries. The Lancet, v. 370, n. 9.593, p. 1.164-1.174, set. 2007. Disponível em: < http://www.thelancet.com/journals/lancet/article/PIIS0140-6736(07)61263-X/ fulltext> Acesso em: 13 ago 2014.

SARACENO, B. Libertando identidades. Da reabilitação psicossocial à cidadania possível. Rio de Janeiro: Te Corá, 2001.

SEN, A. Por que equidade na saúde? In: SEN, A.; KLIKSBERG, B. (orgs.). As pessoas em primeiro lugar. A ética do desenvolvimento e os problemas do mundo globalizado. São Paulo: Cia das Letras, 2010, p. 73-93. 
SNOWDEN, L.R. Explaining mental health treatment disparities: ethnic and cultural differences in family involvement. Culture, Medicine \& Psychiatry, v. 31, n. 3, p. 389-402, set 2007. Disponível em: http://link.springer.com/article/10.1007\%2Fs11013-007-9057-z Acesso em: 13 ago 2014.

SOLOMON, P. et al. Effectiveness of two models of brief family education: retention of gains by family members of adults with serious mental illness. American Journal of Orthopsychiatry, v. 67, n. 2, p. 177-186, 1997. Disponível em: <http://onlinelibrary.wiley. com/doi/10.1037/h0080221/pdf> Acesso em: 13 ago 2014

SPANIOL, L.; ZIPPLE, A.M. Coping strategies for families of people who have mental illness. In: LEFLEY, H.P.; WASOW, M. (Orgs.). Helping Families Cope With Mental Illness. Amsterdam: Harwood Academic Publishers, 1994, p. 131-146.

STENGER, J. The big book of benefits and mental health 2011-12. London: Mind, 2011.

THORNICROFT, G.; TANSELLA, M. Boas práticas em saúde mental comunitária. Barueri: Manole, 2010.

TURATO, E. Métodos qualitativos e quantitativos na área da saúde: definições, diferenças e seus objetos de pesquisa. Revista de Saúde Pública. São Paulo, v. 39, n. 3, p. 507-514, jun 2005. Disponível em: <http://www.scielo.br/pdf/rsp/v39n3/24808.pdf> Acesso em: 13 ago 2014.

TURNER, G.; SHEPHERD, J. A method in search of a theory: peer education and health promotion. Health Education Research, v. 14, n. 2, p. 235-247, abr. 1999. Disponível em: <http://her.oxfordjournals.org/content/14/2/235.full.pdf+html> Acesso em: 13 ago 2014.

VASCONCELOS, E.M. Dispositivos associativos de luta e empoderamento de usuários, familiares e trabalhadores em saúde mental no Brasil. Revista Vivência. Natal, n. 32, p. 173-206, 2007. Disponível em: <http://www.cchla.ufrn.br/Vivencia/sumarios/32/ PDF\%20para\%20INTERNET_32/CAP\%2012_EDUARDO\%20MOURAO\%20 VASCONCELOS.pdf>. Acesso em: 13 ago 2014.

VASCONCELOS, E.M. et al Manual de ajuda e suporte mútuo em Saúde Mental. Rio de Janeiro: Projeto Transversões (Escola de Serviço Social da UFRJ), 2011a.

VASCONCELOS, E.M. Guia para grupos de suporte mútuo em saúde mental. Projeto Transversões (Escola de Serviço Social da UFRJ), Rio de Janeiro, 2011.

VAUGHN, C.; LEFF, J. The measurement of expressed emotion in the families of psychiatric patients. British Journal of Social \& Clinical Psychology, v. 1, n. 2, p. 157-165, jun. 1976.

VELHO, G. Parentesco, individualismo e acusações. In: FIGUEIRA, S.; VELHO, G. (orgs). Família, psicologia e sociedade. Rio de Janeiro: Campus, 1981, p. 77-89.

VIANNA, P. C. de. A reforma psiquiátrica e as associaçôes de familiares: unidade e oposição. 2002. 214 p. Tese (Doutorado em Enfermagem) - Escola de Enfermagem, Universidade de São Paulo, São Paulo, 2002. 
WORLD HEALTH ORGANIZATION. Division of Mental Health. Schizophrenia.

Information for Families. Iniciative of Support to People Disabled by Mental Illness. Geneva: WHO, 1998.

\section{Notas}

${ }^{1} \mathrm{O}$ protocolo de pesquisa foi submetido ao CEP/IPUB e aceito com parecer favorável (Parecer $\mathrm{n}^{\circ}$ 15-Liv.4-11 e CAAE 0044.0.249.000-11). Todos os sujeitos de pesquisa foram informados quanto aos objetivos do projeto e procedimentos metodológicos, bem como quanto aos possíveis riscos e benefícios e o compromisso dos pesquisadores em relação à confidencialidade das informaçôes e da identidade dos participantes. Todos os participantes forneceram consentimento, conforme as normas e princípios da Declaração de Helsinque e da Resolução no 196/96, do Conselho Nacional de Saúde. $\mathrm{O}$ autor declara que não tem nenhum conflito de interesse.

${ }^{2} \mathrm{O}$ projeto de pesquisa e extensão "Familiares Parceiros do Cuidado", base para o presente artigo, foi parcialmente financiado pelo Ministério da Saúde (no componente de Educação em Saúde - Cursos de Capacitação para Familiares) e pela FAPERJ (editais de 2012: processos NE26/110.086/2012 e NE26/111.293/2012). 
Family burden, support groups and coping style among family members of patients in Psychosocial Care Centers

Family members of mental health service users who take everyday care are often subjected to objective and subjective burden. Practical strategies to deal with the task of care and solidarity actions between family members can help improve the quality of life of caregivers and users. This study describes and analyzes strategy developed with Psychosocial Care Centers (CAPS), in collaboration with the family, in order to better know the experience of overload and support self-help initiatives, health education and promotion of autonomy. The collection and analysis of data used qualitative methodology, such as observation and focus groups. Preliminary results identify high levels of overload, good response of family participation in self-help groups and health education activities, and the need to improve and intensify actions developed by CAPS for support and guidance of the family.

> Key words: mental health care; health education; family burden; public mental healthcare. 